\title{
DIGITAL AGRICULTURE PRACTICES IN THE CONTEXT OF AGRICULTURE 4.0
}

DOI: 10.17261/Pressacademia.2017.448

JEFA- V.4-ISS.2-2017(13)-p.184-191

\section{Burak Ozdogan ${ }^{1}$, Anıl Gacar ${ }^{2}$, Huseyin Aktas $^{3}$}

${ }^{1}$ Manisa Celal Bayar University. Manisa, Turkey. burak.ozdogan@cbu.edu.tr

${ }^{2}$ Manisa Celal Bayar University. Manisa, Turkey. anil.gacar@cbu.edu.tr

${ }^{3}$ Manisa Celal Bayar University. Manisa, Turkey. huseyin.aktas@cbu.edu.tr

To cite this document

Ozdogan. B., A. Gacar and H. Aktas, (2017). Digital agriculture practices in the context of agriculture 4.0.. Journal of Economics, Finance and Accounting (JEFA), V.4, Iss.2, p.184-191.

Permanent link to this document: http://doi.org/10.17261/Pressacademia.2017.448

Copyright: Published by PressAcademia and limited licenced re-use rights only.

\begin{abstract}
Purpose- Agricultural production is under heavy pressure based upon increasing world population and significant changes in the climate. In this study, the concept of digital agriculture practices and their effects on agricultural productivity is discussed. An evaluation of current circumstance is made through the cases of Doktar Inc. and Tarla.io which are digital agriculture companies located in Turkey.

Methodology- This study has utilized case method to evaluate the current circumstance of digital agriculture applications in Turkey. Since digital agriculture is an area that is still in early development stage in Turkey, case method is one of the most suitable methods. 11 openended questions and subsequent interviews sent to Doktor Inc and Tarla.io General Managers via e-mail and answers are evaluated with other collected data.

Findings- Digital agriculture applications are in the early development stage in Turkey. The companies that are discussed in the paper have made meaningful progress regarding raising awareness of farmers and other involved parts of agriculture sector in Turkey. While the penetration of the two companies is currently not enough both as volume and quantity, the applications used for digital agriculture by them are parallel with the applications in developed countries.

Conclusion- Digital agriculture practices in Turkey have yet to be implemented in very limited, but there are steps to be taken to acceleration. To develop digital farming in Turkey, supports of government have strategic priorities. In this context, the development of a digital agriculture action plan and supporting of this strategy with related policies and implementations, like in the EU countries and USA, will enable the expansion of agricultural production vision in Turkey. Technopolis and incubation centers of universities will be able to transform the accumulated scientific knowledge into initiatives and create a digital agriculture-focused ecosystem.
\end{abstract}

Keywords: Digital agriculture, big data, innovation, loT, cloud computing. JEL Codes: Q16, 031, M13

\section{INTRODUCTION}

Turkey is located on a geographical position hosted to various civilizations throughout history (Assyrian, Hittite, Byzantine, Seljuk, Ottoman Empire). Because of different climate characteristics according to the regions and Anatolia had also been a world trade center, these civilizations mostly performed agricultural activities in many areas and species (Doğan, Arslan ve Berkman, 2015: 32). 
The report published by Turkish Union of Chambers and Commodity Exchanges (TOBB in Turkish, 2013) states that Turkey, in agricultural production, is among the top 10, with the growing many such as hazelnut or cherry. However, the report shows that Turkey lags behind the world about total factor productivity and Turkey's technical activity has been decreased.

Examining the total of the world on the other hand, the population of the world is expected to reach 9,2 billion by the year 2050. The United Nations Food and Agriculture Organisation (FAO) foresees that farmers should produce $70 \%$ more to satisfy this demand when comparing the year 2006 (WBCSD 2008). According to the OECD (2012) report, water used in agriculture activities for about $70 \%$ of world's total water usage while according to WBCSD (2009) report, water usage of many developing countries causes to over $\% 90$ water consumption.

All these developments require producers to use new generation farming models instead of traditional farming methods in order to preserve sustainability in agriculture. In recent years, with the developments in communication technologies, the sectors that have had no or very limited relationships, seem to feed each other recently and these interactions have resulted in high added value.

Byerlee et.al. (2009) states that globalization affects the agriculture sector and that situation leads to usage of new technologies in their work. They also emphasized that developing countries such as India and Brazil are introducing high value-added agricultural products to the market. In this case, the agricultural export amount of developed countries is mainly composed of products with high added value while innovation makes possible to get products with high added value products.

Innovation is considered as an important way of achieving much more with fewer resources and effort (Avşar and Avşar, 2014: 380). Juma (2015) states that enriching raw material by innovation in accordance with world's changing economic, politic and ecologic conditions, contributes to the processing, packaging, storage, distribution, and safety of food after the production. Tüylüoğlu and Saraç (2012) also reached the conclusion that tending to innovation in agriculture by ensuring the efficiency of production with the whole processes, increases to the economic growth

The agricultural sector has been following technological developments and benefiting from these developments for many years. Developments in satellite, GPS (Global Positioning System), GIS (Geographic Information System) and other mobile communication technologies have provided to an emergence of precision agriculture implementations (López-Riquelme et al. 2016). Especially in recent years, developments in communication technologies such as cloud computing and internet of things have combined with other developments such as artificial intelligence, robotic technologies, and big data analysis allows starting the fourth revolution, in other words, digital agriculture, for the agricultural sector (Dong et al. 2013; Tan 2016).

The theoretical basis of digital agriculture is covered and two cases of digital agriculture applications from Turkey is evaluated in the further sections. Suggestions for the faster development of digital agriculture applications in Turkey are made in the conclusion.

\section{DIGITAL AGRICULTURE}

As expected, agriculture technology sector has been changing like as other sectors and progressing towards becoming a knowledge-intensive enterprise. With this change, traditional production systems have been transforming into modern, productive and innovative systems (Andrade-SanchezandHeun 2010). Recently, the farmers have experienced that managerial activities also turn new paradigms besides production and this situation require more interaction with environmental factors (Sørensenet al., 2010). The concept of agriculture in recent times and in the near future means; the agriculture with water saving, intelligent agriculture, high-quality, high-efficiency, non-polluting agriculture. Digital agriculture is the most effective and necessary approach to realize all these transformations (Yane 2010).

Shen et al. (2010) describe digital agriculture as an implementation of the concept "digital world" proposed in the 90's and the concept "precision agriculture" emphasizes agricultural production processes. Digital agriculture means the using of computer and communication technologies to increase profitability and sustainability in agriculture.

Digital agriculture brings together new opportunities, along with the widespread use of advanced, related, and dataintensive computer technologies, also called the industry 4.0 revolution, to the agriculture. With the digital agricultural tools, which can be used in all agricultural and livestock systems, optimization, high precision, real-time and customized information usage becomes possible of the management of resources, and that creates leverage effect in agricultural implementations (van ES et al. 2016; Deichman et al. 2016). Report written by GIFS (2015) claims that less than $20 \%$ of agricultural lands of the whole world are managed using digital agriculture technologies.

The Digital agriculture, also known as information-based agriculture model, places the processes of providing processing and interpreting digital data based on the agricultural production and management systems (Liang et al. 2002; Zhang 2011). 
Computerized systems and communication technologies need to be interactively benefitted to realize digital agriculture transformation. The components of digital agriculture are shown in Fig.1.

Figure 1: Components of Digital Agriculture

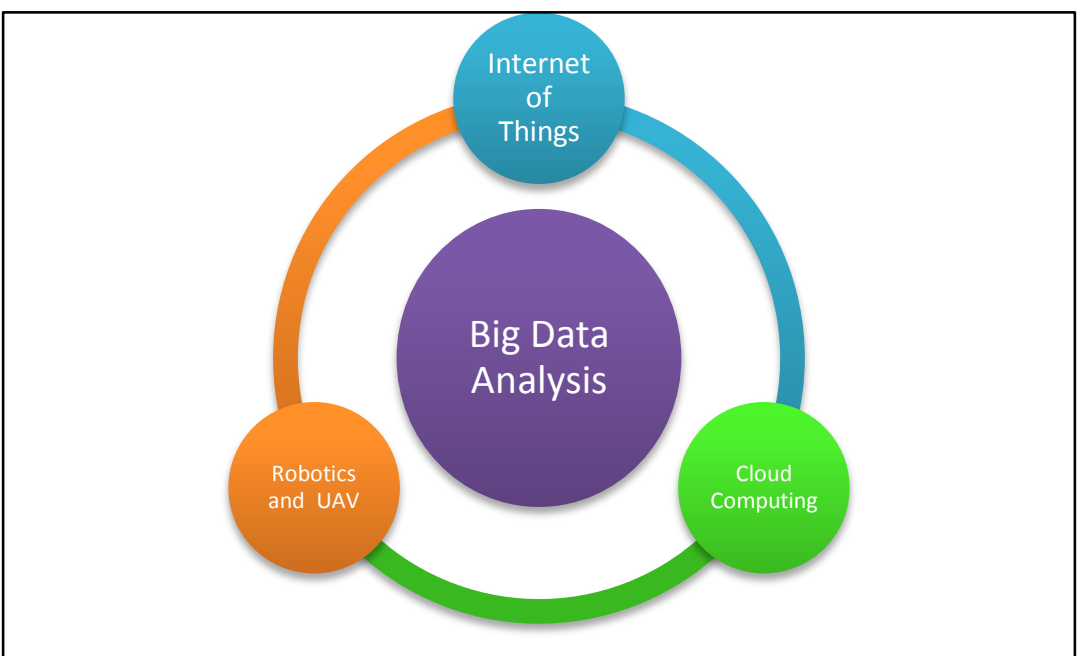

While providing seamless data storage and real-time reporting in the value chain, cloud computing, or cloud can be integrated into the agricultural process where objects can be directly derived from different sources with the Internet of Things (IoT), robotic technologies and drones. Finally, big data analysis is combining large amounts of synchronous and big data from all these different sources into meaningful information (van ES et al., 2016).

\subsection{Big Data and Cloud Computing in Agriculture}

Big data technologies play a vital role in the digital agriculture revolution. In digital agriculture period, while machines are equipped with all kinds of sensors to gauge data in their around, deep learning algorithms and machine behaviors can be generated as a result of analysis of these data. Hashem et.al (2015) defines big data as complements of techniques that require integration forms to distinguish unrecognized values from large scale, various and complex data sets. Big data enables farmers to view all production parameters of real-time operations and improve decision-making processes (IDEAGRO 2015). Data from internal sources have a leverage effect when integrated with data from external big data sources such as market data or competitors (Sun et al., 2013; Wolfert et al., 2017). Data production process is consisting 3 stages: process oriented data from traditional operating systems, data from loT-based machines, and human-derived data (UNECE 2013):

- Process Mediated: Process-driven data, also known as data from traditional operating systems, is related to the activities of an enterprise, its customers, and of its operations (IRMA 2016).

- Machine Generated: Data derived from the internet of machines or objects, obtained from many sensors and intelligent machines used to record and measure agricultural activities. It ranges from simple sensor records to complex computer logs (Hashem 2015).

- Human Sourced: Human-derived data consists of personal experiences that interpreted subjectively. Social media data, personal blogs, and comments, pictures and videos are accepted in this category (Devlin 2013).

More accessible agricultural information makes it compulsory to collect more data and allows deeper insight. This cycle has come through the accumulation of more data and the development of more intensive agricultural knowledge over the years we have been. In recent years, analytic possibilities of agricultural data and sensor data have expanded with the use of multivariate statistical methods and "machine learning" artificial intelligence (Weltzien 2016).

Cloud computing is the basic infrastructure that enables intelligent farming implementations such as scalable calculations, software, data access and storage services (Kaloxylos et al., 2012; Lakshmisudha et al. 2016). Through cloud computing, large-scale data can be stored with low investment cost and instant access to this data becomes possible (Chavali 2014).

Cloud computing contributes to the agriculture sector with a wide range of implementations; 
- Real-time monitoring and guidance in agricultural production: Through cloud computing, agricultural production processes can be instantaneously viewed, controlled, and intervened immediately in the production process if required (Zhu et al. 2013).

- Farm management system: Cloud-based farm management systems enable farmers to enter data into the system time and space independently which enables managerial decisions to be up to date all time (Patel \& Patel 2013; Ault 2013).

- Data flow from external sources: Cloud computing enables instantaneous acquisition of information for weather and other climatic conditions that may be needed during the agricultural activities and can be used directly in decision-making through interrelated devices (Goraya \& Kaur 2015).

\subsection{Internet of Things and Drones in Agriculture}

Porter and Heppelmann (2014) claims that smart and connected devices will enable companies to face with the new competitive opportunities and threats by changing nature of the industry and the nature of competition. Smart and connected devices will lead many enterprises to ask the question "What are we doing?". According to O'Halloran and Kvochko (2015), over the next 10 years, loT revolution will dramatically change sectors such as production, energy, agriculture, transportation and other industrial sectors that generate two-thirds of global GDP, when considered together.

Using loT in agriculture will improve the functionality of existing tools by making the physical world a part of the information system through advanced networked innovative systems. By bringing together information from different sensors and RFID tags, IOT has unlimited potential application areas from monitoring of greenhouses to animals and agricultural machinery (Kaloxylos et al. 2012).

Through sensor networks, agriculture can be established regardless of geographical differences between scientists, farmers, and crops by linking to the Internet of Things. loT technology enables efficient use of resources by allowing producers to make timely and appropriate decisions with real-time and accurate data (Savale et al., 2015; Balamurugan et al., 2016).

IoT supports agricultural enterprises with enough data to calculate how much wheat can be produced in a specific area in a given amount of seed, fertilizer, water and soil chemistry and weather. Agricultural enterprises can prepare sensitive production mixes to increase harvest yields through interconnected intelligent machines and cloud computing-based on big data analysis software (O'Halloran \& Kvochko 2015).

Within the framework of sensitive agriculture implementations, satellites and air vehicles are used to provide information about agricultural areas for a long time. As result of developments in drone technology, the use of these tools for agricultural purposes has become widespread and it has become possible for farmers to access the images they need instantly or by remote control of activities such as pesticide applications at low cost (Malveaux et al 2014; Tripicchio et al). Drones that specially developed for agricultural applications, has sensitive sensors and imaging systems to detect pests and plant diseases (Doyle, van der Wal et al.2015).

\section{DATA AND METHODOLOGY}

The aim of this study is to examine the leading companies of Turkey, Doktar A.Ş, and Tarla.io, in the field of "digital agriculture" with the help case method. According to Yin (1994), the case method asks "why" and "how" to the managers, preventing the manager from manipulating the research questions. In this direction, the data used in the research are obtained by analyzing the written and visual data from the internet environment with 11 open-ended questions and subsequent interviews sent to Doktor Inc and Tarla.io General Managers Tanzer Bilgen and Erdem Erikci via e-mail.

The reason for the use of case method analysis, which is a qualitative research method in the study, is due to the limited time for the research and that the mentioned issue is an area that is still developing in Turkey. With the growing number of companies interested in digital agriculture, qualitative and quantitative methods can be used together and the related literature can be expanded.

Another reason for using the case method in the study is the need for evaluating this subject in more holistic, objective and detailed manner in order not to have any preconceptions about the subject (Sönmez and Alacapınar, 2014: 91). The questions directed to the general manager of Doktar Inc. were sent in the electronic environment on 09.02.2017 and the answers were obtained on 17.03.2017. On the other hand, the General Manager of Tarla.io, Erdem Erikçi, was directed on 07.03.2017 and the answers were obtained on 09.03.2017. The answers and other collected data were evaluated together to reveal the sample application part of the study.

\subsection{Doktar Inc Company Profile}

Doktar was founded in 2012 with the aim of producing digital solutions that will provide higher productivity and lower cost to Turkish farmers. With the services of Doktar projects, developed with various supports of The Scientific and 
Technological Research Council of Turkey (TUBITAK); farmers start to benefit from the experts and information technology in the structure of Doktar to solve production problems, produce with modern and accurate techniques and informed about market demand throughout the season. Defined itself as a company of agricultural technology, Doktar provides farmers agricultural technical information with technology especially to small and medium scale farmers to solve problems in sector applications. The company received $75 \%$ of the grant for two projects with a budget of TL 650.000 within the scope of support program of TUBITAK until this time. The company delivers products and services developed specifically for farmers through many business partnerships and today more than 130.000 farmers use their services.

\subsection{Tarla.io Company Profile}

Tarla.io was established in Bilkent University Technopolis in Ankara at 2014 to design the digital state of agriculture in Turkey and in the world and to present it to the service of the farmers. Tarla.io, which was founded with the support of KOSGEB, has also received TUBITAK support after the establishment, has a foundation philosophy which is using the possibilities of information technology to ensure that people and nature can exist in harmony. Electronical Engineering Inc. parent company of Tarla.io identifies itself as a knowledge project focusing on sensitive agricultural technologies, is an innovation-focused company operating in the aerospace and meteorological fields.

\section{FINDINGS AND DISCUSSIONS}

\subsection{Mobile Services Offered by Doktar Inc.}

The Doktar was established in the Technopolis of Ege University to provide the technical information by utilizing various digital agriculture technologies that farmers need. The service called "Agriculture Doctor" in other words, the company's most comprehensive service currently available is offering personalized agricultural consulting service to farmers from planting to harvesting, agricultural spraying calendar to watering calendar, based on field and product.

To deliver the service to farmers throughout Turkey, Doktar has been in partnership with Turkcell which is the largest GSM operator in Turkey. Both the Agriculture Doctor Service and the Agricultural Consultancy Services of Doktar are provided to farmers by this partnership. "Doktar Phenology Engine" by Doktar Inc developed after the R\&D project, would become a special algorithm that can simulate plant development. Within the scope of this project, 117 plants cultivated in Turkey are simulated and given information about when fertilization will take place from the time of sowing until the time of harvest and when to apply disinfectant, and how to be effective on agricultural revenues. In achieving the agricultural output, phenology plays a role in determining the first date of occurrence of natural events annually. By recording the times of these natural events, Doktar helps farmers to produce products based on more scientific registered data rather than observation. The Phenology Engine is used for farmers who subscribe to the service offered by the Doktor. On the other side, the company also has cloud computing and loT applications.

\subsection{Usage of Cloud, Big Data, and Internet of Things in the Services of Doktar Inc.}

Doktor Inc. as a company focused on digital agriculture, offers all products and services to farmers through the cloud. Thanks to cloud computing, Doktor Inc. can instantly analyze farmers' fields and crop data increases the efficiency by keeping all its systems on the cloud. Cloud computing will ensure that the services currently offered via mobile GSM operators can be offered over all devices that can be connected to the Internet in the short term.

Big data analysis is one of the services that the company plans to offer in the short term. Currently, the necessary infrastructure is being established both in terms of technological sense and in terms of access to big data. Services of the company, which are based on big data analysis, are expected to operationalize within 3 years. In this scope, Doktar who continues the work on the use of loT technologies develops the product named "Mathematics of the Flavor". Based on the Connected Agriculture method; "Mathematics of the Flavor" is based on three basic sources. First is an implementation given to the agricultural engineer, to collect what farmer does and match with the phenological development. Second, agricultural sensors; third is the satellite. Doktar benefits from technologies that try to mathematize differences between farmers who receive different crops under the same conditions. With the application of the Mathematics of the Flavor, the aim can be sampling in a microclimate place in Turkey to sow a product that does not grow in Turkey but grows in Argentina for example. Within this scope, Doktar performs temperature measurements in 8000 different points of Turkey.

\subsection{Mobile Services Offered by Tarla.io}

Tarla.io has the interpretation of measurements made from meteorological stations for each coordinate. Thus, even if there is no measuring station in the region, it still can make the most accurate estimate. In Tarla.io, decision support systems are created by including current or archival meteorological data, information about the biology of plants and soil characteristics. For example, by monitoring the temperature accumulation in a specific region, fertilizer recommendations can be made for the farm by estimating that the wheat is in the bolting phonology. Tarla.io benefits from mobile 
communication technologies to present this analysis to farmers. This service, called TARLA.IO SMS, which is offered to farmers via mobile subscription.

Another reformed mobile service "Toros Çiftçi", has a special model for decomposing of organic matter and chemical fertilizers in the soil, estimating the movements in a soil, and optimizes the plant feed to reduce the environmental pollution caused by fertilization.

\subsection{Usage of Cloud Computing, Big Data, and Internet of Things}

Tarla.io benefits from cloud computing infrastructure, all products and services are provided with its own infrastructure. Besides the data obtained from the installed sensors, the storage and calculation of all data from other sources are carried out via cloud computing systems. Field management system "TARLA.IO ADMIN", that designed to manage the operations of large food companies or agricultural firms, is supporting production planning of its users by presenting plant, weather and soil information in live stream. Service is currently being used by Konya Seker Coop. to manage operations involving 200.000 farmers and 100.000 farms. Operation infrastructure is carried out by entirely cloud computing.

"TARLA.IO RISK" is another service developed by the company for the use of agricultural credit and insurance institutions. It is a system that quantitatively determines the risk involved in agricultural applications by making use of archival meteorological and land data of a specific land. The system, which is designed to work entirely on the cloud computing infrastructure, enables forecasting of the profit that the funds spent on the field will be able to predict in advance and optimize credit and insurance decisions.

Although Tarla.io is a very busy data-driven enterprise, the size of the data it has just received, does not reach the size required for big data analysis. However, all the services of the enterprise which is required to have big data analysis capabilities as the number of users benefiting from products and services increases in the near future, are designed to perform these analyses. When the big data analysis process starts, the efficiency of the products and services offered by Tarla.io will reach a higher level.

"Nooli", an object of Internet of Things, developed within the scope of the project supported by TÜBITAK, is a special sensor that sends the data from the field obtained by measuring the temperature and relative humidity of the air to the center of Tarla.io, thus provides the option of irrigation and spraying to the farmer on this point. The storage and calculation of data from Nooli are also carried out via the cloud system. Nooli sensor allows controlling the situation of fields in real time.

\section{CONCLUSION}

Turkey, which has approximately 23 million hectares of agricultural land, grows field crops in $66 \%$ of this area and grows fruit and vegetables in approximately $20 \% .{ }^{1}$. In recent years, the agriculture sector in Turkey has not been able to grow economically and has faced problems such as productivity and efficiency. ${ }^{2}$ Digital agriculture practices in Turkey have yet to be implemented in very limited and there are steps to be taken to accelerate the transformation process.

Tanzer Bilgen, the founding partner of Doktar Inc, claims that the average age of farmers in Turkey is between 50-55, while the use of mobile and smart devices that are the basis of digital agriculture practices is also decreasing in this age group. It is especially important that young farmers have competence in agricultural technologies and digital agriculture applications, which are considered as sources of agricultural productivity and economic value added.

To develop digital farming in Turkey, supports of government have strategic importance. In this context, the development of a digital agriculture action plan and supporting of this strategy with related policies and implementations, like in the EU countries and USA, will enable the expansion of agricultural production vision in Turkey. It is important to support the establishment and research infrastructures of enterprises aiming to develop domestic digital agriculture practices and to encourage these enterprises like Doktar Inc and Tarla.io. Increasing the number of micro or large scale hybrid initiatives that combine data-oriented informatics expertise with agronomic expertise will open the way for innovative agricultural implementations.

Technopolises and incubation centers of universities will be able to transform the accumulated scientific knowledge into enterprises and create a digital agriculture-focused ecosystem. In this context, Doktar and Tarla.io, both Technopolis companies, are important exemplary enterprises. Besides, the enrichment of higher education curriculum and other educational options, to increase the competence of young farmers in digital farming applications, which will start to increase in the sector in the next few years, can speed up digital conversion.

${ }^{1}$ http://www.tarim.gov.tr/sgb/Belgeler/SagMenuVeriler/BUGEM.pdf

2 https://ekonomi.isbank.com.tr/UserFiles/pdf/tarimsektoru.pdf 


\section{REFERENCES}

Andrade-Sanchez, P., \& Heun, J. T. (2010), Understanding Technical Terms and Acronyms Used in Precision Agriculture, The University of Arizona, Arizona Cooperative Extension Bulletin AZ1534.

Ault, A., Krogmeier, J., \& Buckmaster, D. (2013, July), Mobile, Cloud-Based Farm Management: A Case Study with Trello on My Farm, In 2013 ASABE Annual International Meeting, https://elibrary.asabe.org/abstract.asp?aid=43733\&t=2\&redir=\&redirType=, Accessed: 11.02.2017.

Avşar, D. \& Avşar, G. (2014), Yeni Tarım Düzeninin Tarımsal Üretim Üzerindeki Etkileri ve Türkiye'deki Uygulamalar, Akademik Platform, 379-385.

Balamurugan S., Divyabharathi, N., Jayashruthi, K., Bowiya, M., Shermy, R. P. \&Shanker, R., (2016), Internet of Agriculture: Applying loT to Improve Food and Farming Technology, International Research Journal of Engineering and Technology (IRJET), 3(10), 713-719.

Byerlee, D., de Janvry, A. ve Sadoulet, E. (2009), Agriculture for Development: Toward a New Paradigm, Annual Review of Resource Economics, 1, 15-31.

Chavali, L. N. (2014), Cloud Computing in Agriculture. In Agricultural Bioinformatics, 189-213, Springer India.

Deichmann, U., Goyal, A., \& Mishra, D. (2016), Will Digital Technologies Transform Agriculture in Developing Countries?, Agricultural Economics, 47(S1), 21-33.

Devlin, B. (2013), Business UnIntelligence: Insight and Innovation Beyond Analytics and Big Data, Technics Publications, New Jersey, p.151.

Doğan, Z., Arslan, S. ve Berkman, A.N. (2015), Türkiye'de Tarım Sektörünün İktisadi Gelişimi ve Sorunları: Tarihsel Bir Bakış, Niğde Üniversitesi İktisadi ve İdari Bilimler Fakültesi Dergisi, Ocak, 8(1). 29-4.

Dong, X., Vuran, M. C., \& Irmak, S. (2013), Autonomous Precision Agriculture Through Integration of Wireless Underground Sensor Networks with Center Pivot Irrigation Systems, Ad Hoc Networks, 11(7), 1975-1987.

Doyle, M., How the Internet of Things Helps Grow our Food, Product Lifecycle Report, http://www.ptc.com/product-lifecycle-report/howthe-internet-of-things-helps-grow-our-food, Accessed: 11.02.2017.

Faulkner, A., Cebul, K., (2014), Agriculture Gets Smart: The Rise of Data and Robotics, Cleantech Agriculture Report, http://info.cleantech.com/Ag-Get-Smart-Report-Submit.html, Accessed: 09.02.2017.

GIFS, Global Institute for Food Security (2015), Digital and Computational Agriculture, 2014-2015 Annual Report, http://gifs.ca/wpcontent/uploads/2015/08/GIFS-2014-15-Annual-Report-final.pdf, Accessed: 11.02.2017.

Goraya, M. S., Kaur, H., (2015), Cloud Computing in Agriculture, HCTL Open International Journal of Technology Innovations and Research (IJTIR), 16, 1-5.

Hashem, I. A. T., Yaqoob, I., Anuar, N. B., Mokhtar, S., Gani, A., \& Khan, S. U. (2015), The Rise of "Big Data" on Cloud Computing: Review and Open Research Issues, Information Systems, 47, 98-115.

IDEAGRO (2015), The Era of Digital Agriculture, http://www.ideagro.es/index.php/noticias/89-the-era-of-digital-agriculture, Accessed: 11.02.2017.

IRMA, Information Resources Management Association (2016), Big Data: Concepts, Methodologies, Tools, and Applications, IGI Global Publishing, Hershey, p.279.

Juma, C. (2015), The New Harvest: Agricultural Innovation in Africa. Oxford University Press.

Kaloxylos, A., Eigenmann, R., Teye, F., Politopoulou, Z., Wolfert, S., Shrank, C., Dilinger, M., Lampropoulou, I., Antoniou E., Pesonen, L. \& Nicole, H. (2012), Farm Management Systems and The Future Internet Era, Computers and Electronics in Agriculture, 89, $130-144$.

Lakshmisudha, K., Hegde, S., Kale, N., Iyer, S., (2016), Smart Precision Based Agriculture Using Sensors, International Journal of Computer Applications, 146(11), 36-38.

Liang, Y., Lu, X. S., Zhang, D. G., \& Liang, F. (2002). The Main Content, Technical Support and Enforcement Strategy of Digital Agriculture, Geo-Spatial Information Science, 5(1), 68-73.

López-Riquelme, J. A., Pavón-Pulido, N., Navarro-Hellín, H., Soto-Valles, F., \& Torres-Sánchez, R. (2016), A Software Architecture Based on FIWARE Cloud for Precision Agriculture, Agricultural Water Management, http://dx.doi.org/10.1016/j.agwat.2016.10.020

Malveaux, C., Hall, S. G., \& Price, R. (2014), Using Drones in Agriculture: Unmanned Aerial Systems for Agricultural Remote Sensing Applications, In 2014 Montreal, Quebec Canada July 13-July 16, 2014, American Society of Agricultural and Biological Engineers.

O’Halloran, D., \& Kvochko, E. (2015), Industrial Internet of Things: Unleashing the Potential of Connected Products and Services, In World Economic Forum (p. 40).

OECD (2012), OECD Environmental Outlook to 2050, OECD Publishing, http://dx.doi.org/ 10.1787/9789264122246-en 
Patel, R., Patel, M. (2013), Application of Cloud Computing in Agricultural Development of Rural India, International Journal of Computer Science and Information Technologies, 4(6), 922-926.

Porter, M. E., \& Heppelmann, J. E. (2014), How Smart, Connected Products are Transforming Competition. Harvard Business Review, 92(11), 64-88.

Savale, O., Managave, A., Ambekar, D., \& Sathe, S., (2015), Internet of Things in Precision Agriculture using Wireless Sensor Networks, International Journal of Advanced Engineering \& Innovative Technology, 2(3), 1-5.

Shen, S., Basist, A., \& Howard, A. (2010), Structure of a Digital Agriculture System and Agricultural Risks Due to Climate Changes, Agriculture and Agricultural Science Procedia, 1, 42-51.

Sørensen, C. G., Fountas, S., Nash, E., Pesonen, L., Bochtis, D., Pedersen, S. M., Basso, B. \& Blackmore, S. B. (2010), Conceptual Model of a Future Farm Management Information System, Computers and Electronics in Agriculture, 72(1), 37-47.

Sönmez, V. ve Alacapınar, F.G (2014). Örneklendirilmiş Bilimsel Araştırma Yöntemleri. Genişletilmiş 3. Baskı. Ankara

Sun, Z. F., Du, K. M., \& Zhang, F. X. (2013), Perspectives of Research and Application of Big Data on Smart Agriculture. J. Agric. Sci. Technol, 15(6), 63-71.

Tan, L. (2016), Cloud-based Decision Support and Automation for Precision Agriculture in Orchards, IFAC-PapersOnLine, 49(16), 330-335.

TOBB (2013), Türkiye Tarım Rektörü Taporu 2013, https://www.tobb.org.tr/Documents/yayinlar/2014/turkiye_tarim_meclisi_sektor_raporu_2013_int.pdf, Acceessed: 12.02.2017.

Tripicchio, P., Satler, M., Dabisias, G., Ruffaldi, E. \& Avizzano, C. A. (2015), Towards Smart Farming and Sustainable Agriculture with Drones, In 2015 International Conference on Intelligent Environements, 140-143. IEEE.

Tüylüoğlu, Ş. \& Saraç, Ş. (2012), Gelişmiş ve Gelişmekte Olan Ülkelerde İnovasyonun Belirleyicileri: Ampirik Bir Analiz, Eskişehir Osmangazi Üniversitesi iliBF Dergisi, 7(1), 39-74.

UNECE, (2013), Classification of Types of Big Data, Big Data in Official Statistics, http://www1.unece.org/stat/platform/display/bigdata/Classification+of+Types+of+Big+Data, Accessed: 10.02.2017.

van der Wal, T., Kooistra, L., \& Poppe, K. J. (2015), The Role of New Data Sources in Greening Growth: The Case of Drones, In 2015 OECD Green Growth and Sustainable Development Forum, Paris, 14.12.2015.

van Es, H.M., J.D. Woodard, M. Glos, L.V. Chiu, T. Dutta, and A. Ristow. 2016. Digital Agriculture in New York State: Report and Recommendations. Cornell University, Ithaca, NY.

WBCSD (2008), Agricultural Ecosystems: Facts and Trends, WBCSD Publishing, http://www.wbcsd.org/Projects/Climate-SmartAgriculture/Resources/Agricultural-Ecosystems-Facts-and-trends ,Accessed: 12.02.2017

WBCSD (2009), Water Facts and Trends, WBCSD Publishing, http://www.unwater.org/downloads/Water_facts_and_trends.pdf, Accessed: 12.02.2017

Weltzien C., (2016), Digital Agriculture or Why Agriculture 4.0 Still Offers Only Modest Returns, Landtechnik, 71(2), 66-68.

Wolfert, S., Ge, L., Verdouw, C., \& Bogaardt, M. J. (2017), Big Data in Smart Farming-A Review, Agricultural Systems, 153, 69-80.

Yane, D. (2010, October), Research and Analysis about System of Digital Agriculture Based on a Network Platform, In International Conference on Computer and Computing Technologies in Agriculture (pp. 274-282). Springer Berlin Heidelberg.

Yin, R. K. (1994). Case Study Research. Design and Methods, Applied Social Research Methods Series, 5, (ed. Sage Publications).

Zhang, Y. (2011, February), Design of The Node System of Wireless Sensor Network and Its Application in Digital Agriculture, Computer Distributed Control and Intelligent Environmental Monitoring (CDCIEM), 2011 International Conference on (pp. 29-35). IEEE.

Zhu, Y., Wu, D., \& Li, S. (2013), Cloud Computing and Agricultural Development of China: Theory and Practice, International Journal of Computer Science Issues, 10(1), 7-12. 